\title{
DESIGN AND IMPLEMENTATION OF TCSC FOR 500KV POWER TRANSMISSION SYSTEM
}

\author{
Ali Raza \\ Department of Electrical Engineering, The University of Lahore, Lahore, \\ (Pakistan) \\ E-mail: ali.raza@ee.uol.edu.pk
}

Haroon Farooq Department of Electrical Engineering, University of Engineering \& Technology, Lahore, (Pakistan) E-mail: haroon.farooq@uet.edu.pk

Manzoor Ellahi Faculty of Engineering and Technology, Superior University, Lahore, (Pakistan) E-mail: manzoor.ellahi@superior.edu.pk

Waqas Ali Department of Electrical Engineering, University of Engineering \& Technology, Lahore, (Pakistan) E-mail: engr_waqasali@yahoo.com

Shahid Kaleem Department of Electrical Engineering, The University of Lahore, Lahore (Pakistan) E-mail: shahid.kalim@hotmail.com

Muhammad Nasir Khan Department of Electrical Engineering, The University of Lahore, Lahore (Pakistan) E-mail: muhammad.nasir@ee.uol.edu.pk 


\section{ABSTRACT}

Power transmission capability of a transmission line (TL) depends upon the impedance of the TL, the magnitude and the phase angle difference of the end voltages. Series capacitor largely employed in the transmission lines to increase the transfer capability but create instability problems. Flexible alternating current transmission systems (FACTs) enhance the power transfer through the existing transmission lines with stability intact. Thyristor controlled series compensation (TCSC) is considered in this paper. Impedance of the transmission line is regulated by changing the firing angle of the thyristor. A $500 \mathrm{kV}$ transmission line shunted with TCSC is dynamically implemented in Matlab/Simulink and tested for different sending end voltage and, by changing the impedance of line. Results show the significance of designed control under transient conditions of power system.

\section{KEYWORDS}

Flexible alternating current transmission systems (FACTS) devices; transmission lines; thyristor controlled series compensation (TCSC); stability enhancement.

\section{INTRODUCTION}

Energy is said to be a backbone of a nation's economy. With the passage of time, the world is becoming more automated and electronic and thus the consumption of electricity per person is increased. The human race is going to be more dependent on robots, thus it's important to fulfill the need of electricity. There are two ways to increase the transmission line (TL) capacity. In first choice, need to build new transmission lines to meet the demands. Installations of new transmission lines require feasibility studies, contract signing, electrical and mechanical designs and, material for wires. It is an extravagant choice and requires plenty of time for completion. Second option is to increase the power transfer capability of the existing transmission system. This method doesn't require any feasibility report and cost-effective as well.

A number of researches have been conducted for increasing the bulk power transfer capacity of existing transmission lines [1] - [3]. In early days, power flow control is done by changing taps or via phase shifting transformers. Series reactors were introduced in transmission lines to reduce the power flow and also used to reduce the short circuit current level at some locations when needed. Similarly, capacitors employed in transmission lines to reduce the electrical length and thus to increase the power flow. Hence, series compensation was used on alternate basis according to load condition. However, this kind of compensation introduced transient and stability issues [1]. So, an alternative technique is required to solve these shortcomings. Fixed series capacitors deployed in the transmission lines to increase the power transfer capacity. The introduction of series capacitor causes low frequency oscillations in the transmission system which introduced the effect of sub-synchronous resonance (SSR) in electric power system. Therefore, with the advent of power electronics devices, stated method is replaced by the flexible AC transmission system (FACT). FACTs controllers can not only increase the power transmission capability of the TLs but also offer advantages like damping of low frequency oscillations and mitigation of SSR damping's etc.

IEEE defines FACTS technology as a power electronic system that is used in AC transmission system to enhance controllability and thus increase the power 
transfer capability [2], [3]. The FACTs controllers are categorized according to their generations. Static VAR compensators (SVC), thyristor controlled phase shifters (TCPS) and thyristor controlled series capacitors (TCSC) are known as first generation FACTS controllers. TCSC used to control the impedance of the TL, where a silicon rectifier connected in series combination with a capacitor [4]. In this research, a dynamic TCSC model for $500 \mathrm{kV}$ transmission line is implemented in Matlab/Simulink and tested with two checks: by changing impedance of TL, and by varying the sending end voltage.

The manuscript is organized as follows; effect of capacitors on power transfer when employed in transmission lines is explained in section II. In section III, detailed working of TCSC and employed capacitive mode is described. Section IV and V deal with simulations and results. Finally, conclusions are drawn in section VI.

\section{EFFECT OF CAPACITORS ON POWER TRANSFER IN TRANSMISSION} LINES

The steady state power transfer capability of transmission line is explained through two machine power system model as shown in Figure 1 [5]. Power is transmitted from one terminal (sending end) bus to second terminal (receiving end). Mathematical formulation for power transfer capability is given by:

$$
P_{c}=\frac{V_{s} V_{r}}{X_{L}} \operatorname{Sin} \delta
$$

Where Vs and Vr are sending and receiving ends voltages, respectively, and XL is the indicative impedance of transmission line. $\delta$ represents the phase angle between sending and receiving end voltages. Thus, the power transfer capability of TL largely

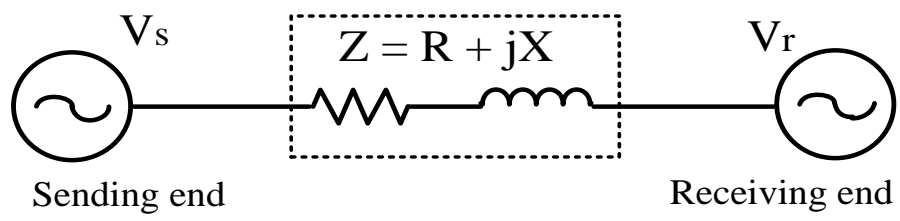

Figure 1. Two machine transmission system.

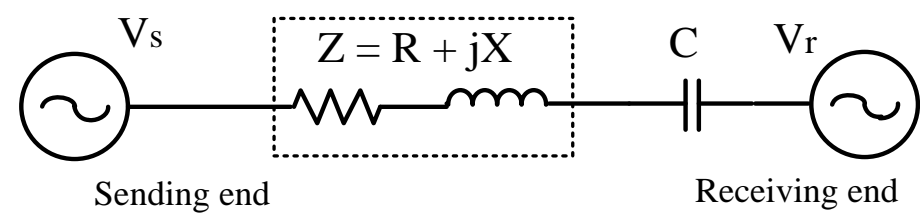

Figure 2. Two machine transmission system with series capacitor.

depends upon the magnitude of the sending and receiving end voltages, phase angle between them and inductance of line.

Conversely, a series capacitor is inserted in transmission system to study the power transfer capability as shown in Figure 2 [5]. Ability of power transmission is increased with such an insertion of capacitors as series capacitors cancel the inductance of transmission line and boost the power flow as:

$$
P_{c}=\frac{V_{s} V_{r}}{X_{L}-X_{C}} \operatorname{Sin} \delta
$$


Where Xc is the capacitive impedance of series capacitors. Due to mechanical switching of series capacitors, transients produced and only fixed value of series compensation achieved [5].

\section{THYRISTOR CONTROLLED SERIES CAPACITOR}

Thyristor controlled series capacitor is a FACTs controller. Mainly, TCSC devices are employed in the series of TLs to increase the power flow. Impedance of TL is regulated by controlling the firing angle of the thyristors. Practically, more than one TCSCs are installed in TL [6]. A TCSC consists of a fixed capacitor which is shunted by a thyristor controlled reactor (TCR) as schematically drawn in Figure 3 [7].

A TCR consists of an anti-parallel thyristors and inductor in series. With TCSC, flexible compensation is achieved because the gate terminal of thyristor is triggered at various firing angles to insert different values of capacitor in series of transmission line. $75 \%$ compensation is achieved, in this paper, by using TCSC. Normally, a TCSC has three modes of operation:

1. Thyristor blocked

2. Thyristor bypassed

3. Vernier operation

In thyristor block mode, thyristors are not conducting and the value of $\alpha$ is 1800 . The effective impedance of TCSC is only because of capacitive reactance of capacitor. In thyristor bypass mode, valves are gated for full conduction and capacitor is bypassed. Practically, some current flows though capacitor but it is negligible. Vernier operation is further categorized into capacitive and inductive mode as shown in Figure 4 [8].

A TCSC operates in inductive region when there is no load condition in power system [9]. Under this mode, TCSC behaves as a source of inductive reactance which decreases the power transfer capability of transmission line. However practically, very rare chances of no load condition in electric power system that is why TCSC is not employed in this scenario. In capacitive mode, TCSC behaves as a source of capacitive reactance to cancel the inductive reactance of TL and thus, increases power transmission capacity of existing transmission line [10]. Practically, power systems are being operated at overload condition due to which, generally TCSC is employed in capacitive mode. TCSC in not operated in resonance region. TCSC can operate within range from $180 \mathrm{o}$ to alpha minimum for capacitive region. If TCSC is allowed to operate at an angle of $180 \mathrm{o}$, no current flows through TCR and the effective impedance of the TCSC is due to the capacitor [11]. If the value of alpha is somewhat between $180 \mathrm{o}$ to alpha minimum, then TCSC reactance is greater than the Xc. The resonance point is reached when $\mathrm{Xc}$ is equal to TCR XL. Required compensation achieved, in capacitive mode, with firing angle range of $690-900$ and $163 \mathrm{~Hz}$ oscillatory frequency, which is 2.7 times the $50 \mathrm{~Hz}$ [12]. Impedance of TL is at the lowest level at 900, that is power transfer capability reduces as the firing angle increases. Impedance is about $120-136 \mathrm{Ohm}$ at time of capacitive mode of TCSC. 


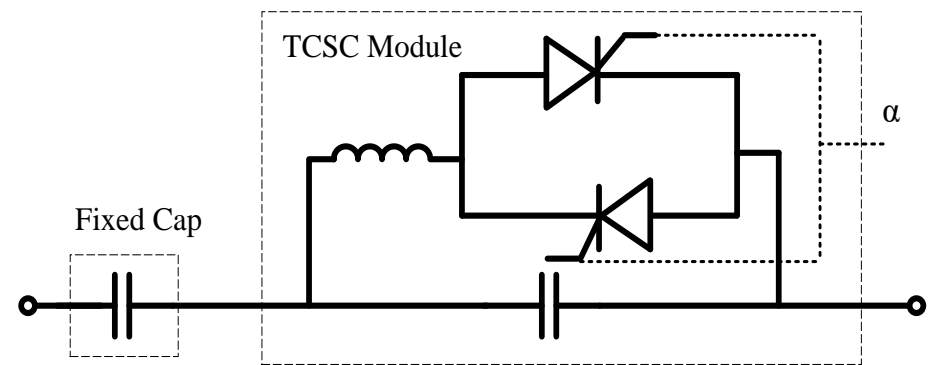

Figure 3. Thyristor controlled series capacitor module.

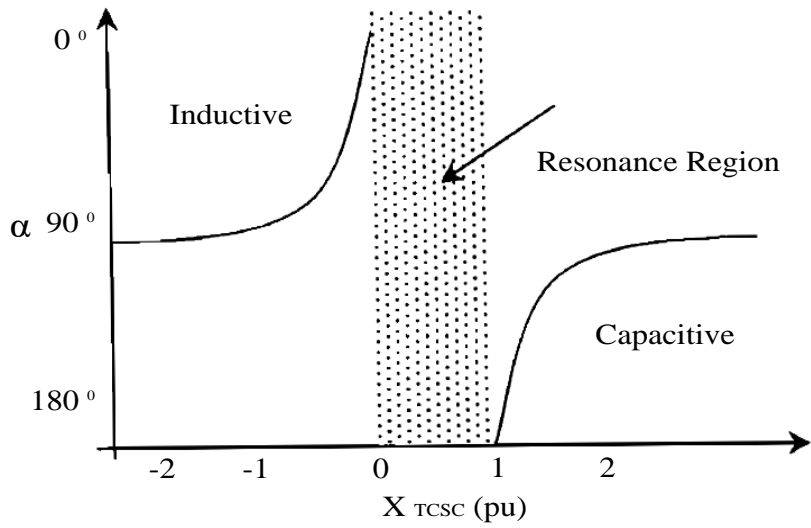

Figure 4. TCSC characteristics.

\section{SIMULINK MODEL OF TCSC FOR 500KV TRANSMISSION LINE}

Mathematical model of TCSC is developed for $500 \mathrm{kV}$ three phase primary transmission line. One TCSC compensates single phase of transmission line, thus for three phases three block of TCSCs are developed. Net reactance of TCSCs is regulated by changing the firing angle of the thyristor. Angle alpha is synchronized with the line current by using the phase lock loop (PLL). Proportional integral (PI) controller is used for the feedback purpose. The developed model includes sending and receiving ends AC voltage sources, TCSC block and the controller. The controller of TCSC includes control unit [12] and firing unit [13] as shown in Figure 5. System under study consists of a programmable voltage source at sending and receiving ends of TL. The purpose of using the programmable voltage source is to vary the voltage at different time instants.

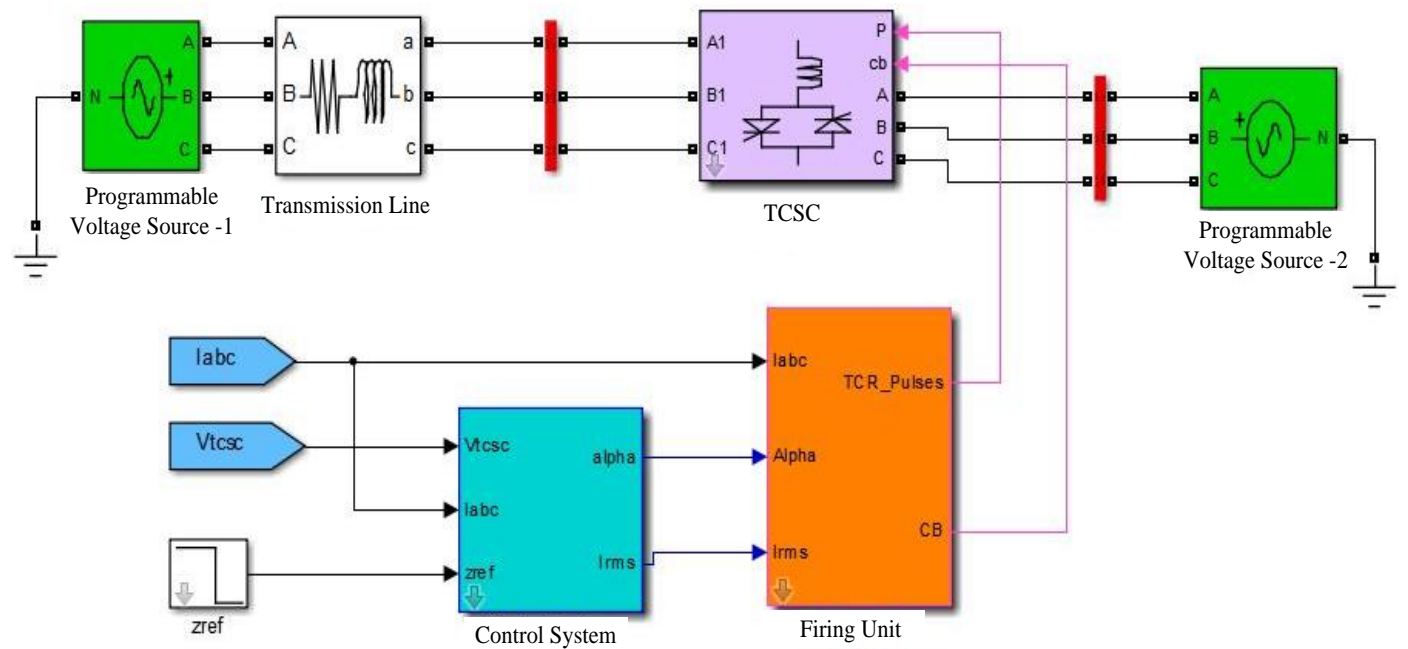

Figure 5. Simulink model of TCSC emplyed within transmission system for $75 \%$ compensation. 


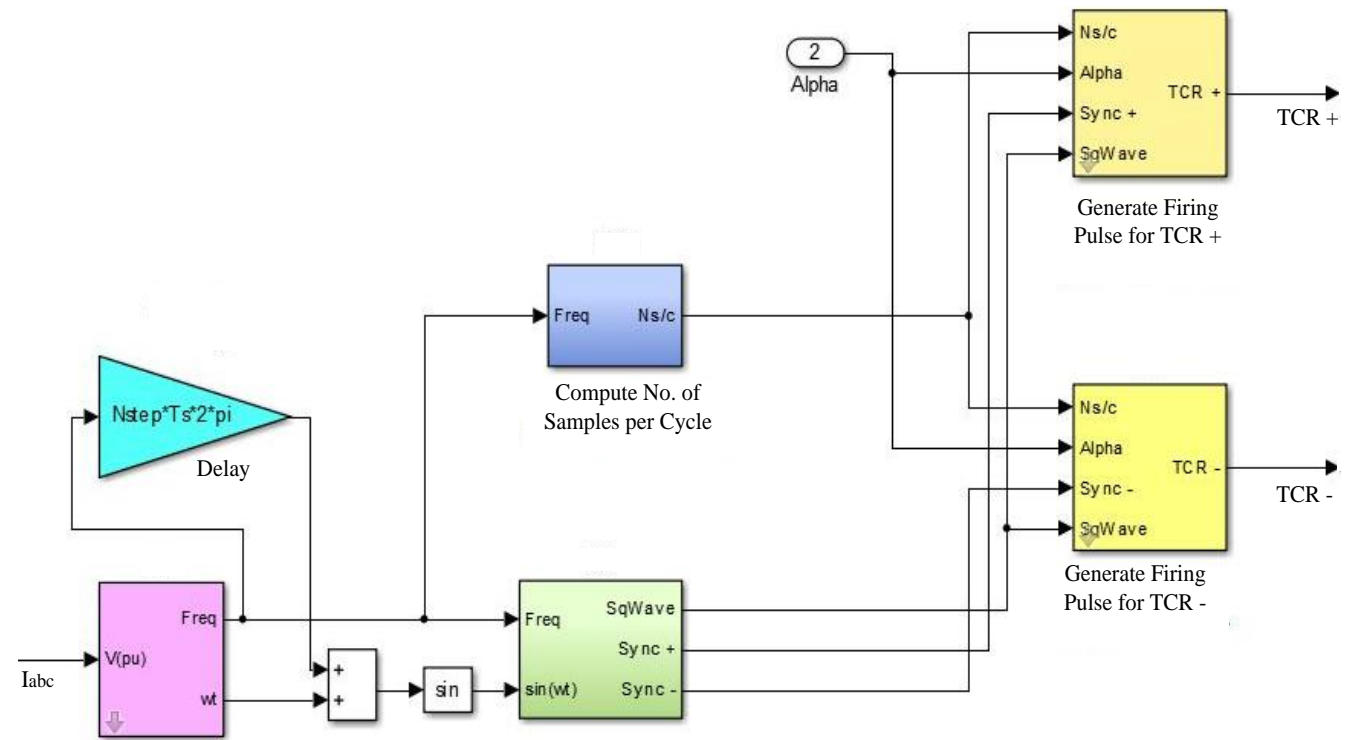

Figure 6. Simulink model of firing unit for single phase.

The series line compensation block consists of TCSC, controller, three phase voltage measurement and scopes for measurement. Triggering pulses for TCSCs are controlled through controller block which consists of control and firing units. Control unit calculate the firing angle based upon the impedance. Initially, the impedance is calculated using RMS values of voltage and current by applying ohm's law, marked as measured impedance. To remove the second order harmonics, it is passed to second order filter [14]. Error is calculated by taking difference of the measured and reference impedances [15]. After that the values are passed through the proportional integral controllers.

In firing unit, line current is synchronized using PLL and then compared and, zero crossing is checked of the line current to generate square wave and to synchronize the pulses as shown in Figure 6. Synchronization pulses are triggered at the start of positive and negative cycles and square wave indicates the duration of a cycle. And then by using discrete time integrator, square wave converted into the saw tooth wave. Rounded method is used to convert alpha into a single value for the comparison of alpha with saw tooth wave. Finally, compared saw tooth wave with alpha value generate triggering pulse for thyristor gate.

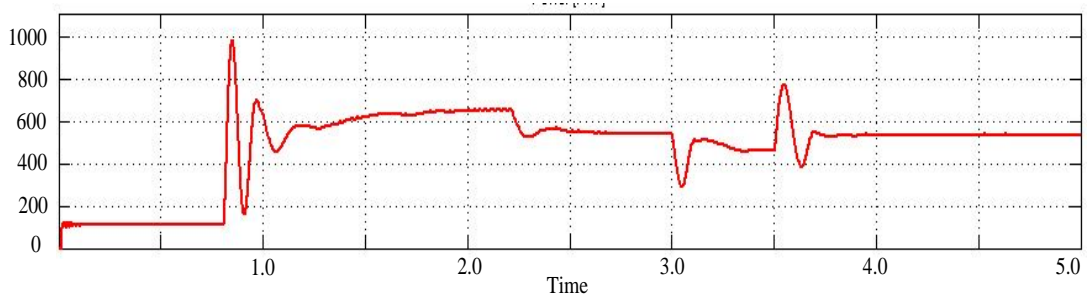

a) Transmitted power via 500kV transmission line

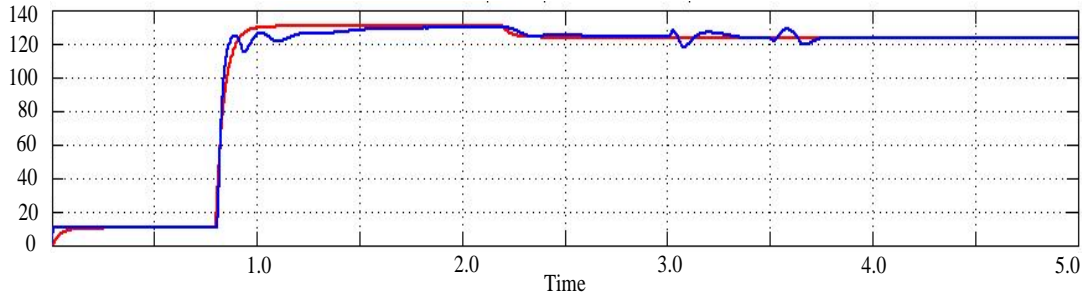

b) Impedance of 500kV transmission line 


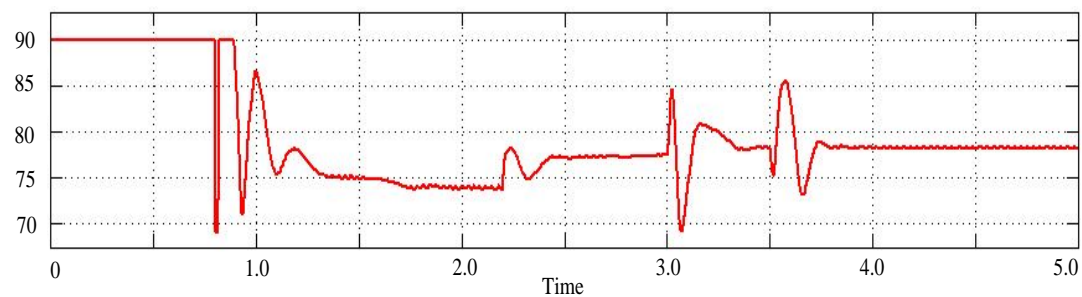

c) Firing angle of TCSC in series with $500 \mathrm{kV}$ transmission line

Figure 7. Transmitted power, impedance of transmission line and firing angle of TCSC inserted in a two machine power system.

\section{RESULTS AND OBSERVATIONS}

Transmission system is designed for $500 \mathrm{kV}$ but due to losses in the lines, receiving end voltages reduced to $477 \mathrm{kV}$. Power, impedance and firing angle profiles of the proposed system are shown in Fig. 7. $115 \mathrm{MW}$ is the power transfer before triggering of TCSC. TCSC operates in capacitive mode and triggered at $0.8 \mathrm{sec}$, power transfer increased to $650 \mathrm{MW}$ and measured impedance follow the reference impedance as shown in Figure 7 (a) and (b), respectively.

$5 \%$ change in reference impedance is applied at $2.25 \mathrm{sec}$ and the response shows that TCSC successfully trace the reference impedance within around $400 \mathrm{~ms}$ as shown in Figures 7 . At $3.0 \mathrm{sec}, 5 \%$ reduction in sending end voltage is introduced and corresponding change in impedance is shown in Figure 7 (b). TCSC tries to match with the reference impedance by compensating the disturbances and lowering the power transfer to $500 \mathrm{MW}$.

Vs returned to 1p.u. at 3.5sec. Corresponding autonomous adjustments of power, firing angle and impedance of system are shown in their respective Figure 7 (a), (b) and (c), respectively.

It is observed that when the voltage drop occurs from programmable voltage source, the TCSC immediately respond to the power oscillation and damp it out but the power transfer does not remain constant before and after the disturbance. Power change from 530MW to 460MW during oscillations due to voltage reduction and returned to original value $(530 \mathrm{MW})$ whence the Vs $=1$ p.u. as indicated in Figure 7 (b).

\section{CONCLUSIONS}

Interconnected power system is employed using $500 \mathrm{kV}$ transmission line. TCSC is used to increase the power transfer capability of transmission system than constructing new lines. A dynamic simulation developed in Matlab/Simulink and tested for with and without TCSC, different sending end voltages, and by changing the impedance of transmission line. Reactive power demand of power system is compensated through TCSC. Results show that voltage regulation is improved, SSR mitigated and more stabled electric power system is achieved. Simulations reveal that installation of TCSC at high tension lines shows better performance. 


\section{ACKNOWLEDGMENT}

The authors are grateful to Prof. Xu Dianguo, IEEE Fellow and Prof. W. Barry Williams for thorough discussion during the research work and thanks to Punjab Higher Education Commission (PHEC) Pakistan for providing financial support to present this research work on international forum.

\section{REFERENCES}

[1] Jalali S. G., Lasseter R. H. and Dobson I. Dynamic Response of a Thyristor Controlled Switched Capacitor. IEEE Transactions on Power Delivery 1994; 9(3):1609-1615.

[2] Discover the World of FACTS Technology - Technical Compendium, Available at: http://www.energy.siemens.com/co/pool/hq/powertransmission/FACTS/FACTS _Technology_.pdf. Accessed on 10 Jan. 2017.

[3] Asare P., Diez T., Galli A., O'Neill-Carillo E., Robertson J., Zhao R. An Overview of Flexible AC Transmission Systems. Electrical and Computer (ECE) technical report, Purdue University; 1994.

[4] Acharya N., Arthit, Yome S., Mithulananthan. Facts about Flexible AC Transmission Systems (FACTS) Controllers: Practical Installations and Benefits. Proceedings of Australian Universities Power Engineering Conference (AUPEC); 2005 Sep 25-28; Hobart, Tasmania, Australia

[5] Deng Y. Reactive Power Compensation of Transmission Lines [MASc thesis]. Montreal, Canada: Concordia University; 2007.

[6] Maruf M, Mohsin A. H. N, Shoeb MD. A, Islam MD. K, Hossain MD. M. "Study of Thyrister Controlled Series Capacitor (TCSC) as a useful FACTS Device. International Journal of Engineering Science and Technology 2010; 2(9).

[7] Yarlagadda V, Sankar B.V, Rao K. R. Automatic Control of Thyristor Controlled Series Capacitor (TCSC). International Journal of Engineering Research and Applications 2012; 2(3): 444- 449.

[8] Rashid H. M. Power Electronics: Circuit Devices and Application. Third edition. Prentice Hall; 1993.

[9] ABB to Enhance 400kV Raipur-Rourkela Transmission Line with State-of-the-Art Flexible AC Solution. Bangalore India: ABB; March, 2003. 02 p.

[10] IEEE Recommended Practice for Specifying Thyristor-Controlled Series Capacitors. IEEE Std. 1534-2009 (Revision of IEEE Std 1534-2002). IEEE; Nov. 202009.98 p.

[11] Mazibuko, Ronnie H. Design and Implementation of a Thyrister Controlled Series Capacitor for Research Laboratory Application [M.Sc. thesis]. South Africa; University of Natal, Durban; 2003.

[12] Jovcic D., Pillai G. N. Analytical modeling of TCSC dynamics. IEEE Transactions on Power Delivery 2005, April; 20(2):1097-1104.

[13] Sen T., Bhattacharjee P. K., Bhattacharya M. Design and Implementation of Firing Circuit for Single-Phase Converter. International Journal of Computer and Electrical Engineering 2005, June; 3(3):368-374. 
[14] TCSC (phasor model) [Internet]. 2016 [cited 2017 Jan 7]. Available from: https://www.mathworks.com/help/physmod/sps/examples/tcsc-phasormodel.html.

[15] Kumkratug, Prechanon. The Mathematical Model and Simulation of Static VAR Compensator in Medium Transmission Line. American Journal of Applied Sciences 2012, May; 9(5). 
Design and implementation of TCSC for 500KV power transmission system

DOI: http://dx.doi.org/10.17993/3ctecno.2019.specialissue.13 